\title{
A CIÊNCIA E A EDUCAÇÃO NAS QUESTÕES AMBIENTAIS
}

\author{
Gustavo Aveiro Lins \\ CEDERJ/ Mestre em Engenharia -Professor SEE/RJ/Observatório Urbano Estado do Rio de Janeiro- \\ OUERJ/UERJ/UN-Habitat \\ $\triangle$ gu.lins@ terra.com.br \\ Thereza Cristina F. Camello \\ Biomédica - Doutora em Ciências Médicas - Microbiologista - Hospital Universitário Pedro Ernesto \\ Universidade do Estado do Rio de Janeiro - UERJ/OUERJ/UERJ/UN-Habitat \\ Josimar Ribeiro de Almeida \\ Observatório Urbano Estado do Rio de Janeiro- OUERJ/UERJ/UN-Habitat
}

\begin{abstract}
Resumo - Este artigo pretende mostrar de que forma a ciência e a educação estão inseridas nas questões ambientais, para isso, o texto foi dividido em quatro subtítulos, são eles: 1. A humanização do espaço geográfico: as questões ambientais contemporâneas, onde é mostrado como o crescimento da civilização afeta direta ou indiretamente o meio ambiente; 2 . A ciência nas questões ambientais: o debate metodológico contemporâneo, neste subtítulo, é discutida a importância de se criar um novo paradigma que sirva para superar as contradições internas e os conflitos metodológicos do processo de conhecimento dos problemas sócio-ambientais atuais; 3. A ciência e a educação nas questões ambientais: o debate do equacionamento, este tópico, faz uma reflexão entre o conceito da razão e a sua aplicação nas questões ambientais, e o último tópico denominado 4. A educação nas questões ambientais: o debate da formação contemporâneo, trata da formação de recursos humanos na área de meio ambiente.
\end{abstract}

Palavras-Chaves: Educação, Ciências ambientais, Ciências.

\section{THE SCIENCE AND THE EDUCATION IN ENVIRONMENTAL SUBJECTS}

\begin{abstract}
This article intends to show how science and education are included in environmental issues, to do so, the text was divided into four captions, they are: 1. the humanization of geographic space: contemporary environmental issues, where it is shown how the growth of civilization directly or indirectly affects the environment; 2 . Environmental Science: the methodological debate, this contemporary subtitle, is discussed the importance of creating a new paradigm that serve to overcome the internal contradictions and conflicts of methodological knowledge of the current socio-environmental problems; 3. Science and education in environmental issues: the debate on the overall equation, this topic, makes a reflection between the concept of reason and its application in environmental issues, and the last topic named 4. Environmental education: the debate of contemporary training, deals with the training of human resources in the area of environment.
\end{abstract}

Key-Words - Education, Environmental Sciences, science. 


\section{A HUMANIZAÇÃO DO ESPAÇO GEOGRÁFICO: AS QUESTÕES AMBIENTAIS CONTEMPORÂNEAS}

COSTA (1987) afirma que a humanização do espaço terrestre sempre implicou em dois processos simultâneos, entrelaçados e de certo modo inexoráveis: a desnaturalização dos espaços naturais-originais e a constituição dos ambientes de vivência e produção.

O modo industrial de produzir introduziu um elemento novo, revolucionário, no processo de desnaturalização do espaço terrestre. Como potencialização concentrada de capitais, força de trabalho, máquinas e matérias primas, a indústria instala-se sob forma de impactos: destrói ou redefine o meio rural, produz ou amplia aglomerações urbanas de todo tipo, redefine completamente as formas de apropriação dos recursos naturais. Usinas de mudanças alteram dois elementos fundamentais do relacionamento entre atividades produtivas e ambientais: a escala e a intensidade dos impactos. Muito embora os ecossistemas possuem mecanismos que operam para conter o impacto dos estressores, pelo menos em algum grau (LINS e ALMEIDA, 2009).

Segundo COSTA (1982), na constituição de novos espaços organizados da era moderna, verificam-se níveis diversos de articulação entre os espaços de vivência e de produção na estrutura e no ambiente urbanos. O modelo inglês sempre se caracterizou pela localização industrial dispersa ao longo de seu território. Na França, seguindo o padrão de centralização política e administrativa do Estado, a atividade fabril tendeu à concentração dentro e em torno da capital. Nos países de industrialização tardia, como o Brasil, as causas do imbricamento entre a atividade fabril e as grandes cidades são de outra ordem. A tendência dos capitais industriais locais ou não é de procurarem as vantagens diretas e indiretas dos meios urbanos, mais desenvolvidos, as chamadas economias de aglomeração, produzindo um espaço único de vivência e produção, constituindo, como em São Paulo, o chamado anel industrializado e de tipo megametropolitano, a gravitar em torno da capital.

Ainda de acordo com COSTA (1987), o modo industrial de produzir atualmente se estende a todo os ramos da atividade econômica organizada, indústrias de serviços, de comunicações, de turismo, até mesmo a agroindústria. A competição entre os planejamentos econômicos e o social ou ambiental tendem a tornar-se crescentemente desiguais. As capacidades de mobilização de recursos materiais de técnicos por parte dos capitais privados ou estatais, além da vantagem de um espaço previamente construído adequado à sua rápida generalização, contrastam fortemente com a relativa fragilidade dos meios colocados à disposição do planejamento e da defesa ambientais. Não se trata, simplesmente, de carência 
de recursos, senão também da desproporção entre métodos muitas vezes artesanais de proteção ao ambiente, diante de métodos industriais de planejar e por em prática a transformação contínua desse mesmo ambiente. Num país marcado pelo subdesenvolvimento industrializado, como é caracterizado o Brasil, a possibilidade dos ambientalistas serem condenados à condição de eternos bombeiros é muito concreta, a persistir a atual correlação de forças entre as políticas econômicas e as políticas ambientais neste país.

A propalada racionalidade e eficácia dos modelos de planejamento, defendida por muitos e negada por alguns. Deve ser examinada à luz da contextualização histórica e territorial dos países nos quais eles são gerados e daqueles para os quais são exportados (ou impostos) e aplicados. É o caso do famoso modelo de Friedmann, cuja proposta para o desenvolvimento incluiu uma estratégia (temporal) a ser seguida ao nível do estabelecimento das prioridades nacionais, tendo por base os estágios de desenvolvimento industrial de cada país. Uma nação que ainda não tenha logrado alcançar o estágio de plena industrialização, por exemplo, não deveria preocupar-se com determinados problemas, já que a prioridade absoluta deveria ser o esforço nacional na criação, a qualquer custo, das condições exigidas por um processo de transição para a própria industrialização. Diversamente, um país já industrializado, segundo ele, deveria voltar suas políticas públicas para as áreas deprimidas, redesenvolvimento de área, ajustes espaciais. Apenas na etapa pós-industrial é que determinado país deverá voltar-se para problemas tais como renovação urbana, ordenamento espacial, problemas metropolitanos e, por último, espaços abertos e meio ambiente. (FRIEDMANN, 1966; BRESSER-PEREIRA, 1981).

O desajuste estrutural entre os tempos (histórico, econômico, social, tecnológico) dá caráter particular a países subdesenvolvidos e industrializados como o Brasil. Pelas idiossincrasias próprias desse tipo de desenvolvimento, com suas modernizações pelo alto ou pela via prussiana ou simplesmente tardias, torna-se praticamente impossível a definição de uma estratégia nacional de desenvolvimento. Ocorre que num país com tais dimensões, diversidade de estruturas produtivas-regionais e simultaneamente de processos diferenciados, quer pela sua natureza, quer pela intensidade, o estabelecimento de uma única política, em qualquer setor, é o mínimo temerária. Isto porque, do ponto de vista do desenvolvimento histórico, social, econômico, urbano, regional, todos os tempos, ou seja, todos os estágios a que se refere Friedmann estão presentes em praticamente todos os lugares.

Nesse sentido, para SANTOS (1979), não há como evitar uma certa irracionalidade que é intrínseca mesmo às políticas públicas e ao planejamento num quadro nacional com estas características que são próprias de seu modo de ser, de sua estrutura global. Em outras 
palavras, há que se preocupar, ao mesmo tempo, e muitas vezes com os mesmos recursos (sempre escassos porque competem permanentemente com outras prioridades) com todas as questões juntas. Esta questão nos remete à necessidade de incorporar a noção de escala à análise ambiental, o que contribuiria para evitar muitos equívocos no trato desse tema. A definição das escalas para estudo, reflexão e ação por parte das organizações que manejam a questão ambiental, é fundamental para o estabelecimento das prioridades e das políticas globais e setoriais. Alguns fenômenos que têm afetado o meio ambiente são zonais ou mundiais, como os climáticos, enquanto há outros de expressão regional, caso da Amazônia e sua cobertura florestal.

COSTA (1986) assinala que países como o Brasil têm que formular suas políticas públicas ambientais num quadro de extremas dificuldades, já que enfrenta, de um lado, demandas sociais poderosas a disputar permanentemente os recursos orçamentários e, de outro, forças endógenas e exógenas que impulsionam uma espécie de contra-corrente capaz, senão de anular, pelo menos de fragilizar ao máximo a eficácia de tais políticas.

A irreversibilidade do processo em curso de transformação do país em economia predominantemente industrial, mediante a adoção devia ser não propriamente clássica, ou seja, um violento crescimento industrial sem as pré-condições normais a este processo, tem gerado um desenvolvimento estruturalmente marcado pela presença de pontos de estrangulamento de variadas qualidades e intensidades, dentre eles as violências contra o ambiente.

A transformação do meio rural, cuja ponta de lança desse processo tem sido o crescente uso de mecanização e tecnologias intensivas no manejo da terra, assiste a um processo de extensão às atividades rurais do modo industrial de produzir. Esta expansão acelerada das fronteiras agrícolas em largas faixas do território verifica-se à custa do grande empreendimento agrícola e industrial, em sua maior parte do tipo predatório.

A explosão urbana, especialmente a metropolitana, é um fenômeno visível hoje em praticamente toda a América Latina e em especial nos países em vias de industrialização, que tende a expressar-se preferencialmente sob a forma metropolitana.

\section{A CiÊnCIA NAS QUESTÕes AMBIENTAIS: O DEBATE METODOLÓGICO CONTEMPORÂNEO.}

Conforme MORAES e COSTA (1984), de acordo com o pensamento moderno, cabe à ciência a tarefa de explicar os fenômenos do mundo, tornando a investigação sobre o próprio 
conhecimento o objetivo maior da filosofia. Os métodos de interpretação da realidade emergem, neste contexto, como a via de relacionamento entre estas formas de saber. $\mathrm{O}$ método expressa uma relação entre ciência e filosofia. É através dele que o cientista define os procedimentos analíticos. A opção metodológica traz em seu bojo a adesão a uma lógica e a aceitação de certas posturas frente às questões gnosiológicas básicas, como a do entendimento do próprio ato cognitivo.

O positivismo lógico (ou neo-positivismo) nomeia seu modelo de encaminhamento analítico e explicação do real como "método científico", colocando todas as formulações que lhe são alternativas na rubrica de conhecimentos destituídos de objetividade, logo "nãocientíficos". Nesta concepção, assim como a do positivismo clássico (ou "empírico"), é possível um alto nível de analogias entre as distintas ciências, dada à base comum metodológica. Procedimentos, verificações e conclusões são intercambiadas independente das qualidades específicas dos fenômenos analisados. Há um rígido critério de cientificidade, que atravessa e ignora as particularidades das áreas de sua aplicação. Existem, contudo, outros métodos que se pretendem específicos de uma classe particular de fenômenos, ou mesmo de uma só ciência. Neste último caso estaria a sociologia compreensiva de Max Weber ou a teoria psicanalítica de Freud, dedicadas ao estudo de realidades bem circunscritas e com procedimentos intimamente ligados aos objetos em exame (KOLAKOWSKI, 1974; MARI, 1974).

Detecta-se uma grande diversidade dos métodos científicos e variedade dos seus conteúdos, podendo-se daí intuir a complexidade do debate metodológico contemporâneo. Negá-la constitui o grande equívoco da roupagem atual da postura cientificista. Tal postura, ao perder a dimensão filosófica do trabalho científico, serve de veículo eficaz de manipulação do cientista ao distanciá-lo da reflexão acerca de sua responsabilidade social, conforme observa HABERMAS (1980). Reduz-se o método à técnica e o cidadão ao técnico.

Para MORAES (1987), a incursão pela metodologia permite exatamente o resgate dessas implicações perdidas. A retomada da discussão dos princípios que norteiam os vários procedimentos operacionais de pesquisa, do esclarecimento dos pressupostos lógicos, da explicitação dos conceitos e categorias utilizadas, e, principalmente, da reflexão sobre a relação política/ciência num patamar mais elevado do que o do panfletarismo ou do partidarismo.

Há muito que se clarear na discussão metodológica acerca da problemática ambiental. Um caminho fértil de indagação seria o rastreamento das visões sobre os elementos básicos desse universo em diferentes sistemas filosóficos, desse modo elucidando as concepções de 
natureza, de sociedade e da relação sociedade-natureza, ao nível das grandes matrizes metodológicas das ciências modernas.

SILVA e POMPEO (1987) consideram que o enfoque epistemológico no tratamento da questão ambiental procura responder pela necessidade de uma postura interdisciplinar que contemple a percepção da globalidade dos problemas sócio-ambientais do universo a ser pesquisado.

A atual abordagem do método científico, cujos postulados foram formulados por Descartes em 1637, quando aplicada a um problema ambiental contemporâneo, apresenta duas limitações fundamentais: a primeira é a que diz respeito ao primeiro postulado cartesiano, qual seja que a cientificidade é oriunda somente do conhecimento comprovável. De acordo com MORIN (1984), não se admite, portanto, que o estabelecimento do conhecimento sobre um determinado universo possa ser influenciado pela parte não conhecida do universo e ainda não científica.

A outra limitação diz respeito ao segundo postulado, pelo qual deve-se dividir as dificuldades/problemas do universo a ser pesquisado em tantas partes quantas forem necessárias para seu entendimento. Hoje, pode-se afirmar, com segurança, que nunca um postulado foi tão amplamente aplicado e com tanta influência em toda interpretação da história do homem como este. Para CAPRA (1986), a limitação desta abordagem no tratamento da questão ambiental se dá pelo resultado fragmentado que é obtido na leitura da realidade ambiental.

A contradição histórica existente entre a formulação cartesiana do método científico e a sua aplicação aos problemas contemporâneos é a de que, hoje, vive-se uma realidade onde, para um mesmo universo, podem-se fazer tantas leituras diferenciadas quantas se quiser. A especialização do processo de conhecimento leve à produção de uma massa de informações construídas com linguagens não compreensíveis entre si e que, ao final, não conseguem fornecer o conhecimento global do universo pesquisado, por mais paradoxal que possa parecer. Segundo MORIN (1984), torna-se necessária, portanto uma adequação do método científico que seja capaz de proceder à leitura da complexidade dos problemas sócioambientais, apresentando resultados de conhecimentos compatíveis entre si, através de um processo interdisciplinar crescente com linguagens compreensíveis e integradoras da globalidade do universo da pesquisa. GONÇALVES (1987) destaca, igualmente, a necessidade de repensar o paradigma de cientificidade. $\mathrm{O}$ isolamento de cada cientista dentro de sua especialidade, cada vez mais separado não só das demais regiões do saber, mas também no interior de cada região, levou a uma concepção caótica do todo. 
SILVA e POMPEO (1987) destacam que uma vez estabelecida à complexidade dos problemas relativos à questão ambiental, faz-se necessário discutir as possíveis formas de construção do conhecimento sobre o objeto da pesquisa, que são a uni, a multi, a inter e a transdisciplinaridade.

A visão unidisciplinar do método científico vem conduzindo as ciências a uma crescente especialização, fazendo com que o objeto da pesquisa seja decomposto em partes. A motivação disciplinar é isolada e se traduz numa visão parcial do universo, levando a um entendimento distorcido do mesmo, uma vez que as relações entre as suas partes quedam-se omissas. Sua contribuição, entretanto, é fundamental no processo de conhecimento, para a identificação e tratamento de variáveis específicas.

Conforme KENDALI e MACKINTOSH (1979), a multidisciplinaridade é originária da percepção da interveniência de muitos elementos na explicação do universo considerado. A conceitualização heterônoma de um problema define as disciplinas envolvidas que, utilizando-se isoladamente de seus métodos e técnicas, apresentam contribuições particulares à compreensão do mesmo. Estas contribuições são dirigidas à coordenação de pesquisa que procede a integração dos produtos parciais sem que ocorra, entretanto, explicação a nível horizontal tanto na elaboração do conjunto quanto nos métodos de investigação empregados.

Segundo COIMBRA (1985), a interdisciplinaridade é um processo de conhecimento que, utilizando uma estrutura multidisciplinar, procura estabelecer vínculos intencionais na compreensão e explicação do universo da pesquisa, superando desta forma a excessiva compartimentação científica provocada pela especialização das ciências modernas. Ela é resultante da integração horizontal das metodologias de cada especialidade envolvida no processo. Esta integração deve ocorrer já a nível de inventário, de modo a produzir conhecimentos e informações integradas e compreensíveis entre si. Neste processo observa-se uma redução da característica heterônoma, presente de forma marcante na multidisciplinaridade, e um conseqüente aumento da autonomia na regulação dos conflitos metodológicos já que a interação entre as disciplinas ocorre sem a presença de uma coordenação que especifique as contribuições individuais. A ação se desenvolve a partir de um entendimento comum das questões criando-se assim as condições necessárias para discussão das diferentes abordagens metodológicas. Para GONÇALVES (1987), a interdisciplinaridade não pode ser erguer se for mantida prisioneira de um pensamento herdado que a negou. Em outras palavras, não se pode superar o paradigma atomísticoindividualista nos mesmos marcos filosóficos que o geraram. 
SILVIA e POMPEO (1987) afirmam que a transdisciplinaridade caracteriza-se pela construção de uma imagem do universo de pesquisa comum a todas as especialidades, imagem esta a partir da qual se estabelece, então, uma linguagem comum no processo de produção do conhecimento. Desta forma tenta-se superar as diferenças de conceitos e enfoques sobre um mesmo objeto que as especialidades introduzem no processo. É a possibilidade de profissionais de diferentes formações científicas comunicarem-se através de conceitos e categorias compreensíveis entre si, na construção do conhecimento, que caracteriza a transdisciplinaridade. A integração entre as disciplinas não se faz somente a partir de suas metodologias específicas, como no processo anterior, mas também através da incorporação de um glossário dado pela linguagem comum. Assim, a leitura das questões desenvolve-se por um método particular oriundo da integração e incorporação de elementos metodológicos entre as disciplinas envolvidas, resultando em análises que transcendem o simples somatório das partes.

Ainda conforme SILVIA e POMPEO (1987), a inter e a transdisciplinaridade, enquanto práticas de produção de conhecimento levam a uma visão holística do mundo, através da compreensão da realidade em função de totalidades integradas cujas propriedades não podem ser reduzidas a unidades menores. A interatividade, por sua vez, enquanto processo de construção de soluções, leva a uma prática mediadora de conflitos através da criação de espaços de ação comunicativa, ampliando os conceitos de democracia e autonomia. Para entender estes indicadores como valores norteados de uma prática de pesquisa, julgam-se necessário inseri-los numa percepção sobre a natureza da questão ambiental.

A visão fragmentada e mecanicista do mundo levou às ciências e à política uma prática que hoje se torna cada vez mais ineficiente para o entendimento da complexidade dos problemas, sejam eles de que natureza forem. No início deste século, e ao longo de suas primeiras três décadas, consolidou-se uma nova visão do comportamento da matéria que iria revolucionar o estabelecido por Descartes e Newton, não no sentido de que seus postulados deixavam de ser científicos, mas sim de que já não podia aplicá-los de forma generalizada a todos os fenômenos.

Para CAPRA (1986), a nova visão do comportamento da matéria foi dada pela física através da Teoria da Relatividade, desenvolvida por Einstein a partir de 1905, e pela Teoria Quântica, desenvolvida por vários cientistas, entre eles Max Plank, Niels Bohr, Louis de Broglie, Erwin Schrodinger, Wolfgang Pauli, Werner Heisenberg, Paul Dirac, além do próprio Albert Eisntein, a partir de 1925. A primeira teoria abalou os alicerces da visão mecanicista do mundo, com a relativização do tempo, do espaço, da matéria e da energia, 
consideradas absolutas na visão newtoniana. A segunda teoria foi ainda mais contundente, quando, ao estudar o comportamento das partículas subatômicas, identificou-lhe uma dualidade, ora se comportando como onda, ora como partícula, dependendo dos instrumentos com as quais eram examinadas.

De acordo com MORIN (1986), com estas contribuições da física moderna, o universo passa a ser visto não mais na forma de uma máquina, composta de uma infinitude de partes e objetos passíveis de serem decompostos e que para sua restituição bastava o seu somatório, mas sim como um todo dinâmico, indivisível cujas "partes" estão essencialmente interrelacionadas e que para serem entendidas necessitam de modelos de representação globais, do tipo orgânicos, sistêmicos, auto-organizados, ecológicos e holísticos.

Neste contexto, complementam SILVA e POMPEO (1987), a questão ambiental, enquanto contradição homem-biosfera, pode ser considerada como uma crise de percepção sobre a natureza dos problemas ambientais, colocando-se como um assunto a ser tratado pela filosofia. Parte-se da constatação de que nenhuma corrente filosófica ocidental, seja por delimitação ideológica, seja por formulação histórica, contempla, hoje, a questão ambiental sob forma de contradição fundamental, preocupando-se com o estudo de sua natureza.

A questão ambiental é, então, colocada como denominador comum a ser contemplado pelas diferentes correntes filosóficas e seus respectivos métodos, presentes no processo de conhecimento dos problemas sócio-ambientais atuais. Não se trata, portanto, de criar uma filosofia para o grupo, mas sim de um paradigma que sirva para superar as contradições internas e os conflitos metodológicos do processo.

MORIN (1977) considera que não se trata, obviamente, de retomar o enciclopedismo, mas de buscar articulações organizacionais entre esferas disjuntas. Para GONÇALVES (1987), não se pode pensar que se trata de uma questão simplesmente de metodologia ou de linguagem como se faz crer a filosofia analítica. A necessidade de que a linguagem científica seja coerentemente estruturada, o que pressupõe a lógica, não nos deve iludir. Esta é uma exigência do método científico. No entanto, a lógica é uma condição necessária porém não suficiente para dar conta da diversidade dos seres. Não pode haver um método universal e, consequentemente, uma linguagem universal que cubra todo e qualquer ente que colocamos sob observação científica. A relação entre o particular e o universal continua um desafio e, portanto, aberto. 


\section{A CIÊNCIA E A EDUCAÇÃO NAS QUESTÕES AMBIENTAIS: O DEBATE DO EQUACIONAMENTO}

Para GONÇALVES (1987), o conceito clássico de razão deve ser efetivamente revisto - não se pode mais aceitar a idéia de uma razão soberana. É preciso reconhecer: a razão que na perspectiva iluminista se pretendia emancipadora ficou assimilada à dominação quando o Estado que oprime e domina o faz e fala em nome dela. É compreensível que rebelar-se contra o Estado é rebelar-se contra a razão, a ciência e a técnica. Segundo ROUANET (1987), existe uma outra razão que longe de se opor-se à visa permite combater as forças que verdadeiramente a asfixiam. Trata-se, pois, de um chamamento à razão crítica. $O$ desenvolvimento da razão não foi e não é linear, não sendo tampouco imune ao desenvolvimento histórico que a inventa e institui. Por ser contraditória, exige lucidez. Em nome da razão, a humanidade pode se libertar, mas quando se faz ideologia em nome dela, se

oprime. É preciso ainda distinguir entre a razão instrumental, em torno da qual se desenvolve o controle da natureza, da razão comunicativa, que se desenvolve no plano das normas e cujo terreno é a intersubjetividade. Confundir esse dois planos, como tem sido feito, é uma das características do capitalismo tardio e do socialismo burocrático, onde tudo se transforma em questão técnica.

De acordo com GONÇALVES (1987), num contexto em que procura debater a questão do meio ambiente é preciso que se tomem muitos cuidados pelo envolvimento de múltiplos aspectos: do ético ao tecnológico, do econômico e político ao cultural. E quando se trata da questão do meio ambiente, é comum se propugnar por um uso racional dos recursos. E aqui é preciso ficar atento para os múltiplos aspectos que a palavra racional invoca. A razão técnico-científica não é a razão no seu todo. Segundo HABERMAS (1977), a razão é mediatizada numa relação intersubjetiva onde entram normas, valores e objetivos históricosculturalmente constituídos e constituintes. Neste campo, a razão instrumental técnicocientífica tem os seus limites por tratar-se de um campo prático (no sentido Kantiano) e não técnico. É o campo do conflito, do consenso, da luta, enfim, da política. Para ROUANET (1987), a razão científica só é crítica com relação ao mundo objetivo das coisas e não com relação ao mundo social das normas. $\mathrm{O}$ fato desses campos serem confundidos tem conduzido normas e valores a ficarem suprimidos em nome da razão instrumental, técnica. Aí se encontra uma das razões do crescente autoritarismo tecnocrático das sociedades contemporâneas. 


\section{A EDUCAÇÃO NAS QUESTÕES AMBIENTAIS: O DEBATE DA FORMAÇÃO CONTEMPORÂNEA}

Os critérios ora sintetizados, descritos em maior detalhe em FORMACIÓN AMBIENTAL (1991), reúnem algumas características importantes no âmbito da formação de recursos humanos na área de meio ambiente. Inicialmente, uma das dificuldades básicas para incorporação da dimensão ambiental nos estudos superiores decorre da escassez de pesquisadores e docentes que tenham partido dos métodos científicos e pedagógicos tradicionais, avançando no sentido da elaboração de métodos interdisciplinares de pesquisa e de conteúdos curriculares que integrem saberes de diferentes campos do conhecimento.

Os avanços teóricos e metodológicos gerados nos últimos vinte anos, assim como o acúmulo de conhecimentos disponíveis nas diversas áreas do meio ambiente (desde o conhecimento biológico e ecológico até aquele que incorpora a dimensão social e cultural), fazem necessário passar das experiências isoladas de formação ambiental efetuadas durante os anos setenta e oitenta a um processo de maior profundidade teórica e alcance prático, baseado na cooperação interinstitucional.

Somente na medida em que as diferentes universidades assumam uma responsabilidade mais ativa no processo de formação ambiental a partir de suas próprias capacidades, integrando pesquisa, ensino e ações práticas, será possível formar profissionais com uma visão global e integradora do meio ambiente.

A Educação Ambiental estabelece a necessidade de novos métodos pedagógicos e de administração do saber, de acordo com os princípios do desenvolvimento sustentável, a gestão participativa e a administração coletiva dos processos ecológicos e produtivos, que assegurem uma oferta sustentável de recursos naturais e de satisfações para a sociedade.

A formação ambiental incorpora uma nova ética e uma nova epistemologia que incidem na transformação das necessidades e motivações individuais, integrando as capacidades afetivas e cognitivas do homem na organização produtiva da sociedade, gerando um potencial ambiental de desenvolvimento que articule seus recursos naturais, culturais e tecnológicos.

A formação ambiental encontra na ação de defesa preservação e aproveitamento produtivo do ambiente um importante recurso didático e uma fonte de experiência pedagógica. Assim, a gestão ambiental é ao mesmo tempo um fim prioritário da formação e um campo privilegiado de práticas para o processo educativo. 
Para articular os processos de produção, transmissão, aquisição e aplicação de conhecimentos com os processos de administração dos recursos ambientais, a formação ambiental deverá fomentar a pesquisa participativa das universidades com as comunidades urbanas e rurais, sobre os problemas ambientais prioritários que os afetam, e na implementação de projetos de gestão ambiental a nível local. Para isso terá que elaborar critérios básicos e métodos para conseguir a participação das organizações de base em atividades de formação ambiental, para melhorar a capacidade de autogestão e a participação na tomada de decisões das próprias comunidades.

A formação ambiental deve ser permanentemente avaliada, para que possam ser incorporadas as experiências e saberes que surgem ao longo do avanço do processo de gestão ambiental, renovando seus métodos pedagógicos e seus conteúdos curriculares com um enfoque global e sistêmico sobre os processos ambientais. Isto requer a transformação do conhecimento disciplinar compartimentalizado, como os métodos pedagógicos e as práticas tradicionais de ensino.

Compreender a biodiversidade, que no caso do Brasil abriga $23 \%$ de todas as espécies do planeta, (LINS e ALMEIDA, 2005) e o ambiente como um saber emergente, em seu caráter diverso e diferenciado, e em um processo em construção, que aparece como um campo de externalidade das diferentes ciências e disciplinas científicas. Não se trataria de internalizar uma dimensão ambiental homogênea para as diferentes ciências. Cada disciplina deve definir o campo e conteúdos do saber ambiental que são assimiláveis a seus paradigmas tradicionais.

A interdisciplinaridade no campo ambiental não se constitui como a soma e articulação dos conhecimentos e saberes existentes. O saber ambiental é um processo de revisão crítica e reconstrução criativa de conhecimentos a partir do questionamento que oferece a problemática ambiental às limitações explicativas e à ineficácia aplicativa do saber disponível.

O saber ambiental interdisciplinar aparece como um saber heurístico, orientado por uma perspectiva global e complexa da articulação de processos naturais e sociais de distintas ordens de materialidade, níveis conceituais e escalas espaço-temporais.

O saber ambiental emerge em um marco conceitual, epistemológico e metodológico capaz de compreender as múltiplas causas dos problemas ambientais e os diversos processos que se articulam na gestão ambiental. Isto implica em uma crítica dos modelos, metodologias e concepções reducionistas do ambiente: ecologismo, economicismo, sociobiologia, positivismo lógico, individualismo metodológico. 
A formação de formadores deve incorporar a análise de teorias e métodos que se abrem até a articulação de processos de diferentes ordens de materialidade: estruturalismo genético, análise de sistemas complexos, epistemologia ambiental do desenvolvimento do conhecimento, relativismo cultural e gnosiológico, os quais permitam desenvolver novos paradigmas teóricos integradores e articular conhecimentos de diferentes disciplinas na prática da gestão ambiental.

Os cursos de formação de formadores devem analisar os conceitos básicos do pensamento ambiental: gestão ambiental; qualidade de vida; crítica à sociedade de consumo e desperdício; bases ecológicas do desenvolvimento sustentável, contas do patrimônio de recursos naturais e culturais, potencial ambiental de desenvolvimento. 


\section{REFERÊNCIAS BIBLIOGRÁFICAS}

BRESSER-PEREIRA, LC. Estado e Subdesenvolvimento Industrializado. São Paulo: Brasiliense. (1981).

CAPRA, F. O Ponto de Mutação. São Paulo: Cultrix. (1986).

COIMBRA, J.A.A. O Outro Lado do Meio Ambiente. São Paulo: CETESB. (1985).

COSTA, WM. O Processo Contemporâneo de Industrialização. São Paulo. Dissertação de Mestrado.(1982).

COSTA, WM. O Modo Industrial de Produzir no Campo: Um Aspecto Atual da Modernização Capitalista. São Paulo. (1986).

COSTA, WM Bases epistemológicas da questão ambiental: determinações, mediações e contradições. (1987).

FRIEDMANN, JR. Regional Development Policy: a Case Study of Venezuela. Cambridge Mass. (1966).

HABERMAS, J. Ciência e Técnica enquanto Ideologia. São Paulo: Abril (Coleção Os Pensadores). (1980).

KENDALL, S, MACKINTOSH, EE. Management Problems of Polydisciplimary Environmental Research in the Unversity Setting. Ontario: Canada/MAB Comité. (1979).

KOLAKOWSKI, L. La Filosofia del Positivismo. Roma. (1974).

LINS, G.A. e ALMEIDA, J. R. Biopirataria no Brasil: Uma análise histórica.. Mundo \& Vida: Alternativas em estudos ambientais. Volume 6 (1/2), pp.38-43 (2005)

LINS, G.A. e ALMEIDA, J. R. Caracterização Estatística de Recurso Hídrico do Domínio Tropical Atlântico. Revista Brasileira de Pesquisa e Desenvolvimento. Volume 10, numero 2,pg. 68-75. 2009.

MARI, EE. Neopositivismo y Ideologia. Buenos Aires: Universitaria. (1974).

MORAES, ACR. Bases epistemológicas da questão ambiental: o método. In: Anais do II Seminário Nacional sobre Universidade e Meio Ambiente. Belém: SEMA/UFPA. (1987).

MORAES, ACR E COSTA, WM. Geografia Crítica: A Valorização do Espaço. São Paulo: Hucitec. (1984).

MORIN, E. La Mèthode 1: la Nature de la Nature. Paris: Sevil. (1977).

MORIN, E.O Problema Epistemológico da Complexidade. Lisboa: Europa-América. (1984).

MORIN, E. Para Sair do Século XX. Rio de Janeiro: Nova Fronteira. (1986). 
ROUANET. As Razões do Iluminismo. São Paulo: Cia. das Letras. (1987).

SANTOS, M.. Economia Espacial: Críticas e Alternativas. São Paulo: Hucitec. (1979).

SILVA, DJ E POMPEO, CA. Bases metodológicas para o tratamento da questão ambiental. In: Anais do II Seminário Nacional sobre Universidade e Meio Ambiente. Belém: SEMA/UFPA. (1987). 